\title{
El periodismo: una mirada desde la sociología de las noticias ${ }^{1}$
}

\section{Ernesto Pablo Juárez Meléndez:2}

1 En ocasión del inicio de la Licenciatura en Periodismo, en la UACJ (agosto 2011), este artículo pretende contribuir con un panorama general de las teorías que abordan el quehacer periodístico desde la sociología.

2 Becario Conacyt (2011-2014), del programa de Doctorado en Ciencias Sociales (PNPC), terminal Estudios Culturales

Correo electrónico: pjuarezmelendez@gmail.com

Fecha de recepción: 10 de octubre de 2011

Fecha de aceptación: 10 de agosto de 2012 


\section{Introducción}

$\mathrm{N}$ ecesitados siempre en el ámbito académico de continuas revisiones a los estados del arte de nuestros campos de investigación, abordo este primeramente, con una "introducción", en la que ofrezco una visión general de los aportes a partir de contextualizar la discusión desde la importancia de la información periodística en la sociedad democrática y en la mexicana en particular. Se hace el planteamiento de los orígenes de esta discusión desde la teoría sociológica a partir de Max Weber, para luego ubicarme en el contexto norteamericano que es el que ha tenido mayor influencia en la investigación en México. En el apartado "delimitación de los estudios", ubico el campo de los estudios de periodismo, con una revisión de los marcos conceptuales y sus distintos niveles de análisis, que invocan al fenómeno a partir de su papel en la democracia. En el apartado "la noticia: el producto de los periodistas", aclaro en qué consiste esta como construcción y sitúo su centralidad a partir de los valores noticiosos que establecen la noticiabilidad de un hecho. Más adelante, en "la cuestión metodológica”, hago una revisión de las distintas aproximaciones y el debate epistemológico que subyace en las aportaciones investigativas más importantes. En el apartado "la profesión del periodismo", contextualizo la discusión sobre la objetividad del ejercicio periodístico. Luego, en "los filtros de la información", abundo en las teorías de la selectividad noticial, con especial énfasis en la teoría de los gatekeepers, y por último, en "La complejidad del ejercicio periodístico", expongo la argumentación sobre las presiones a que se ven sometidos los profesionales de la noticia y los dilemas que enfrentan.

Voltear a ver a los medios noticiosos para explicarnos su influencia, es también voltear a donde estas reflexiones se fundaron con la aparición de las gacetas en el siglo XVIII y el apogeo de la prensa en el siglo XIX y principios del XX. En este transitar, se hizo evidente como problema a investigar, la preponderancia de los medios informativos, en una sociedad necesitada de información.

En la actualidad existe un seguimiento a esa preponderancia de los medios por parte de organismos internacionales, como lo señala el 
colombiano Jesús Arroyabe (2008), que informa de un estudio realizado por la ONU en el 2004, donde establece que el 70\% de la información noticiosa que obtiene el ciudadano proviene de los medios de comunicación. En México, de acuerdo a Javier Esteinou (2010), de la UAM Xochimilco, el 67\% de los ciudadanos obtiene la información de la TV.

Ya desde los inicios de los estudios sobre la comunicación de masas, el sociólogo Robert Park (1940), observó que la sociedad se vale de los medios informativos para tener un "conocimiento" de la realidad. Idea explorada antes por Max Weber, que aquí abordamos con el propósito de hacer una revisión del origen y desarrollo del campo sociológico aplicado al periodismo y su producto la noticia.

Max Weber, desde 1910, en su disertación: Para una sociología de la prensa, plantea la pregunta inicial del campo de la sociología de

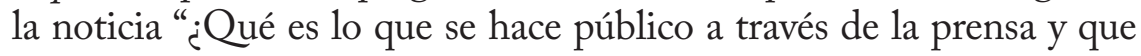
no?” (Weber, 1992: 252). Desde aquí Weber dimensiona el objeto a investigar:

Los contactos de los periódicos con los partidos, aquí y en otros países, sus contactos con el mundo de los negocios, con todos los innumerables grupos y personas que influyen en la vida pública y son influidos por ella, suponen un campo impresionante para la investigación sociológica.

(Weber: 253)

Para Humanes e Igartua (2005), compiladores de las teorías de comunicación social, el programa de análisis weberiano adelanta áreas de investigación de la comunicación que se desarrollarán a partir de los años treinta y cuarenta, que no solo se interesa por los contenidos del periódico, sino que plantea otro tipo de cuestiones relacionadas con la formación, situación y requisitos profesionales de los periodistas, la recepción de los contenidos y los efectos tanto individuales como sociales.

Mauro Wolf (2002), hace también una compilación que ha sido multicitada en diversos trabajos que abordan el tema, considera que el 
enfoque del estudio de los periodistas proviene de la Sociología de las Profesiones aplicada a los medios.

(...) los emisores desde el punto de vista de sus características sociológicas, culturales, de los estándares de carrera que siguen, de los procesos de socialización a los que están sometidos, etc. Desde esta perspectiva son estudiados algunos factores < externos> de la organización del trabajo, que influencian los procesos productivos de los comunicadores. (Wolf: 223)

En Wolf encontramos una línea que se ubica en el nerwsmaking, esta concibe a la noticia como un producto, una idea que ampliaremos más adelante cuando habremos de referirnos a la construcción de la noticia.

Es quizá uno de los trabajos más significativos en este campo, el de Pamela Shoemaker y Stephen Reese que en su obra Mediating the message (1991) inscriben la actividad de la producción de noticias desde lo que llaman Sociología de los medios (media sociology). Dice Reese: "La investigación, con frecuencia llamada 'media sociology', ha ayudado a explicar como las noticias son construidas - por individuos- dentro de una ubicación social y ocupacional.” (Reese, 2001: 645)

Los conceptos desarrollados por Shoemaker y Reese se extienden a otros 'productores de sentido', ${ }^{1}$ como los denomina Eric Maigret (2005), en donde encuentran similitudes (como el género emergente infotainment) con los productos mediáticos de entretenimiento.

Sobre este particular María Elena Hernández precisa:

Los autores Hirsh (1977) y McQuail (1994) sostienen también que este tipo de análisis (Media Sociology) puede aplicarse a diferentes productos culturales elaborados por los medios (cine, telenovelas, libros, música), aunque la mayoría de los trabajos existentes se ha centrado en la información periodística, y por tanto el campo se ha venido desarrollando en torno a este tipo de producto. (Hernández, 1997: 212)

1 El sentido lo caracterizamos aquí como el contenido conceptual o emocional del mensaje. 
Conviene resaltar que el campo que aquí nos interesa es el que propiamente concierne a los periodistas y su producto la noticia.

\section{La delimitación de los estudios de periodismo}

En su recopilación sobre los avances en México de la investigación en este campo, Cervantes (2005) al igual que Hernández (1997), utilizan el término de Sociología de la producción o productores de la noticia. Coincido en que esta propuesta precisa la naturaleza del campo de estudio en la actividad del periodista como productor de la noticia. A su vez Lozano, (2007) de manera más amplia, utiliza Sociología de la producción de los mensajes, aunque admite el uso del término usado por Cervantes y Hernández. Mientras que en la enunciada por Wolf (2002), Shoemaker y Reese (1996) y otros como Eric Maigret (2005)2, se deja abierto a la multiplicidad de profesiones de los trabajadores de los medios, como la industria del entretenimiento.

Sobre la taxonomía del estudio de los emisores y la diversidad de los enfoques nos lo aclara, Cecilia Cervantes:

Las noticias y la manera como éstas se generan han dado lugar a la realización de una multiplicidad de estudios que se integran de manera general en torno a un subcampo de investigación de la comunicación conocido como "sociología de la producción noticiosa" (Sociology of News Production), el cual se ubica dentro del campo más amplio de la sociología de los medios (Media Sociology). Dentro de dicho subcampo es posible reconocer diversos enfoques y 'subobjetos'. (Cervantes, 1996: 51)

En el mismo texto la autora precisa las contribuciones para el análisis de los emisores a partir de las categorías creadas por Paul Hirsh

2 Sobre este particular, Maigret en su Sociología de la comunicación y de los medios, hace la distinción entre lo que propiamente es el estudio de los periodistas y el de los productores de programas de TV y cine, al separar, en capítulos distintos, el estudio de los emisores: capítulos 11 para los periodistas y 12 para los emisores de la industria del entretenimiento. 
(1977) y revisadas y adicionadas en la primera edición de 1991 de Mediating the Message de Shoemaker y Reese, para reconocer el nivel de influencia de los distintos contextos en el que se desempeña el periodista:

Para Hirsh, en el nivel individual se ubican factores de influencia relativos a las creencias, actitudes, valores y formación de los periodistas; en el organizacional se analizan factores que tienen que ver con las rutinas y ciclos de producción de las noticias, y en el institucional se ubican los factores relativos a la vinculación entre la organización de medios con otras empresas de comunicación y con otras instituciones sociales en general. En el caso de Shoemaker y Reese, (...) en el nivel ideológico se analizan aspectos tales como la vinculación entre los medios y el control social, el poder, la ideología y la hegemonía. (Cervantes, 1996: 53)

Así el trabajo de Paul Hirsch: Occupational, Organizational and Institutional Models in Mass Media Research: Toward a Integrated Framerwork (1977), desde una perspectiva multinivel, estableció puntos de partida para el análisis de los constructores del mensaje periodístico. Por su parte Dimmick y Coit (1983:361-389) han reconocido hasta nueve niveles de análisis, haciendo una deconstrucción analítica de los tres niveles de Hirsch.

Más adelante, lo que hacen Shoemaker y Reese, es agregar el nivel ideológico, que reconocen como una categoría que envuelve a las otras:

Las presiones de los anunciantes y el público, las fuentes (de información), la economía de mercado y otros. ¿Por qué estos factores externos a los medios se relacionan con los medios de la manera en que lo hacen? Por los imperativos culturales e ideológicos sobre el rol que los medios masivos deben jugar en la sociedad. (Shoemaker y Reese, 1996: 252) 
El nivel ideológico refiere a conceptos que están presentes en los neomarxistas (Gramsci por ejemplo), en la escuela crítica de Frankfurt y en la corriente de los Cultural Studies, que permiten un análisis macrosociológico a diferencia de las particularidades que ven los de carácter micro tal y como lo plantea Becheloni (1986): "Por un lado están los estudios macrosociológicos que hacen referencia al ámbito institucional y a la lógica productiva de los medios. Por otro lado están los estudios microsociológicos que se interesan por la organización especifica de los mass media" (Becheloni en Alsina: 1989, 146), y agrego: por los individuos que integran estos medios.

Por lo pronto, la contribución de Shoemaker y Reese ha sido el detonante para múltiples investigaciones con base empírica (Cervantes, 2005); como lo fue mi propio trabajo sobre los criterios noticiosos en los periodistas juarenses a partir del estudio de caso como fueron los motines en el CERESO municipal en el 2007 (Juárez, 2009) y el trabajo pionero también en Ciudad Juárez, de Leticia Castillo (2001), Noticias y culturas en Ciudad Juárez, en el que expone la valoración noticiosa dominante en esa época. ${ }^{3}$

Como hilo conductor, siempre es conveniente tener en cuenta la importancia de los estudios sobre los periodistas: "en razón de su posición central en el proceso democrático y de su proximidad a los medios intelectuales" (Maigret: 2005, 272), sin dejar de considerar la cercanía con las élites del poder instituido.

En esta línea de reflexión Hernández Ramírez, nos explica a partir de Altschull (1984), el que estos estudios hayan tenido mayor intensidad en los Estados Unidos:

La investigación sobre la producción de noticias no se desarrolló en ningún otro país como en los Estados Unidos, en donde emerge de una preocupación pragmática. En la historia del periodismo estadounidense se registran acontecimientos y características de la práctica periodística que generan entre algunos sectores de poder la necesidad de conocer los mecanismos del periodismo, para encontrar

3 Las dos tesis de maestría disponibles en la Biblioteca Central de la UACJ. 
una forma de controlar los excesos mostrados por la prensa a principios del siglo XX (...) contra los excesos del poder económico, contra el credo del darwinismo social y contra su economía del 'dejar hacer-dejar pasar'. (Hernández: 1997, 213)

Preocupación que buscó ser atendida por la Comisión Hutchins en 1947, que reunió varios a académicos de la época ${ }^{4}$ para tratar de establecer un código deontológico a partir del concepto de responsabilidad social de la empresa. Por cierto, este es un tema que apenas encuentra en México su pleno debate hoy en día.

Mientras, la discusión sobre el papel de la prensa en la sociedad democrática ya tiene una larga tradición en países como los Estados Unidos, así lo muestra el trabajo de académicos como Dennis McQuail, en su Introducción a la teoría de comunicación de masas (2000), en donde elabora una de las mejores síntesis sobre este tipo de estudios y su evolución.

Para ampliar más esta versión del interés norteamericano en este campo, Maigret rastrea el origen de los estudios sobre la prensa desde un enfoque inicial basado en Merton y Lazarfeld, desde la perspectiva funcionalista y liberal de las profesiones, que sirvió para el estudio de una profesión como la del periodista en busca de su legitimación. Esto me parece uno de los aspectos centrales de este campo: la legitimación de la profesión periodística.

Es conveniente aquí clarificar la perspectiva funcionalista en este tipo de estudios, dado que ha sido el enfoque dominante:

4 La comisión estaba integrada por destacadas personalidades del mundo académico, entre ellas John M. Clark, John Dickinson, William E. Hocking, Harold D. Lasswell, Arthur M. Schlesinger y George N. Shuster. Los debates y conclusiones produjeron una reflexión en la que se alertaba sobre los riesgos de la prensa y los medios en general, en un escenario en el que la propiedad aparecía cada vez más concentrada en pocas manos y se acentuaban los intereses mercantiles. Por lo que se creía oportuna una autorregulación de los medios, acorde con el espíritu y las necesidades de la democracia, para evitar así, la no deseada intervención del Estado. En sus conclusiones la comisión sostuvo que el mercado no consideraba las libertades públicas — como el derecho a la información - por lo que eran necesarios mecanismos garantistas. 
El enfoque funcionalista contempla el trabajo noticial como un problema a ser resuelto: 'El problema de la selección de las noticias y la definición de las noticias'. El enfoque principal es en la rutina normal de funcionamiento, no la crisis, lo marginal, y la construcción de tensiones al interior entre las instituciones dentro de la sociedad. ${ }^{5}$ (Reese, 2001: 645)

Como apuntábamos al inicio, cualquier estudio sobre el periodismo y su producto la noticia se relaciona con una inquietud en los estudios de sociología de la comunicación, que se pueden rastrear desde el siglo XIX. En Europa por ejemplo, Kurt Lang ${ }^{6}$ reporta en Alemania, estudios con una base empírica que se arraigan en la preocupación central por el estudio de la opinión pública (Orozco, 1997). José Marques de Melo, (decano de los investigadores brasileños) en su conferencia magistral en el IX Congreso Latinoamericano de Investigadores de la Comunicación (ITESM, Edo. de México, 2008), coincide en señalar desde una perspectiva histórica, que el campo de investigación tiene sus inicios, también desde el siglo XIX en los Estados Unidos.

En México, el interés por el campo de estudio lo aclara Hernández Ramírez:

(el) por qué obtenemos el tipo de noticias que obtenemos o por qué las noticias son como son, es representativa de la investigación de la comunicación en términos más amplios y permite sustentar la certeza de que los aportes de esta especialidad beneficiarán, al menos, en tres aspectos: en el conocimiento de la práctica periodística, en la enseñanza del periodismo, y en el establecimiento de relaciones de la investigación con los medios. (Hernández, 1997: 209)

Con respecto al último aspecto que se menciona, han sido escasos los estudios sobre los emisores en México, ya que quizá no hay en el

5 El entrecomillado es de Reese, $c f r$. Alexis S. Tan, Mass Communications Theories and Research.

6 De acuerdo con Humanes e Igartua, Kurt Lang es el que rescata el papel de Weber como el iniciador de los estudios de periodismo. 
medio periodístico una aceptación de su utilidad. Situación muy distinta a Estados Unidos, donde al inicio de las investigaciones, fueron periodistas que luego obtendrían sus doctorados (principalmente en la Universidad de Chicago, donde nacieron los estudios sociológicos norteamericanos) los que fundarían una tradición que conjuntaba el ámbito académico con el ejercicio profesional del periodismo. Tales fueron los casos de Robert Park, Walter Lippman, en sus inicios y posteriormente David White, entre otros.

Así es como Cecilia Cervantes (2005) — que junto a Hernández y González Molina, son considerados autoridades en la materia en nuestro país - apunta que algunos autores (Wolf, 1987; Shoemaker y Reese, 1993; Lozano, 1996) ubican las raíces de estos estudios en las investigaciones de David White (1950), sobre los gatekeepers o selectores de noticias; mientras que otros ubican su origen en los trabajos de Robert Park (1940) y Walter Lippman (1925), representativos de la Escuela de Chicago (Tuchman, 1978; Alsina, 1989; Hernández, 1995).

En otra mirada, más allá del árbol y que contempla al bosque de la actividad periodística en la sociedad contemporánea, están perspectivas como la Economía Politica Crítica de la Comunicación, con los trabajos de los ingleses Peter Golding y Graham Murdock a la cabeza; Herman y Chomsky en Estados Unidos; Armand Mattelart, Marques de Melo y otros en Latinoamérica, y en México en particular con: Javier Esteinou, José Carlos Lozano y el mismo pionero en estos estudios, Gabriel González Molina ${ }^{7}$; que entre otras cuestiones, analizan las organizaciones y sus productos mediáticos, como las noticias, en el entramado de los intereses de la élite dominante: iniciativa privada y la intervención pública gubernamental: Bajo el aspecto macrosociológico de la Economía Política Crítica de la Comunicación, la visión empresarial se encuentra implícita en cualquier análisis de

7 El trabajo de González Molina, primero en este campo en México, es desarrollado en su tesis doctoral (1989), donde analiza el racional corporativo de los trabajadores de la noticia en Televisa. En él establece que los trabajadores asumen los intereses de la empresa como suyos en las rutinas productivas. 
rutinas productivas en el periodismo de una organización inscrita en la cultura capitalista occidental (Alsina, 1989: 142). Aun cuando existen grandes coincidencias, en los principales exponentes de la corriente de la Economía Política Crítica, hay una diferencia significativa entre ingleses (Murdock, Golding y otros) y norteamericanos (Chomsky, Herman). Para los primeros, la intervención de un estado fuerte puede moderar los intereses particulares que se manifiestan en los medios, mientras que para los segundos el estado posibilita y refuerza una posición corporativa desde los medios. Esto no es extraño, dado los modelos de televisión europeos, donde la presencia del estado ha sido determinante; a diferencia de los norteamericanos, donde las grandes corporaciones detentan el usufructo de las señales de TV concesionadas por el estado. Desde los Estudios Culturales, este es un asunto central en la elaboración y consumo de productos culturales incluidas las noticias.

Stuart Hall (1978), uno de los más destacados exponentes de esta corriente, sostiene que los discursos conllevan, en la neutralidad aparente de los periodistas, la visión de las clases hegemónicas dominantes; los miembros de las élites son los primeros en tener acceso a los medios. A este proceso Stuart Hall le llama el efecto estructurante " $\mathrm{y}$ dado que dominan los códigos simbólicos legítimos, los poderosos imponen a los periodistas una primera definición..." (Hall en Maigret p.283). Los estudios culturales, más allá de la propiedad de los medios, atienden la compleja imbricación de estos con las formas de vivir e interpretar la realidad de la gente en el contexto de la globalización de las formas culturales hegemónicas.

\section{La noticia: el producto de los periodistas}

¿Cuál es la característica entonces de este mensaje construido por el periodista?

La noticia es la definición periodística de un hecho. Pero no de cualquier hecho, porque no cualquier hecho sirve como noticia. Averiguar que condiciones ha de reunir un 
hecho para ser noticia y que rasgos tienen en realidad los hechos que los medios toman y venden como noticia es importante, porque nos permite comprender como trabajan los medios y como usamos todos los hechos que son noticia. (Gomis, 1991: 89)

Desde ese punto de partida las organizaciones mediáticas, donde se inscribe el trabajo del periodista, reciben una especial atención pues la noticia no puede ser entendida fuera del contexto organizacional. De acuerdo a Rodrigo Alsina y otros autores, la noticia es una construcción social, porque el periodista que la construye (la produce), cumple una función en la sociedad de la que forma parte: "podemos establecer que los periodistas tienen un rol socialmente legitimado e institucionalizado para construir la realidad social como realidad pública y socialmente relevante" (Alsina, 1989: 30)

Esta afirmación de Alsina, parte desde la perspectiva de Berger y Luckmann en La Construcción de la Realidad Social (1999). Recordemos que para ellos la realidad social es diferente de la realidad natural, caótica a los sentidos: "La realidad social es entonces un orden que se construye a través de la influencia recíproca de los individuos, a partir de un primer acto: el de la comunicación y su estructura: el lenguaje." (Berger y Luckman, 1999: 51), todo ello contextualizado por la cultura. Percibimos al mundo con los demás, de aquí que la realidad social es conformada por la mediación intersubjetiva de la realidad natural. Por cierto esta perspectiva está ausente del modelo de Harold Lasswell $(1948)^{8}$ y de la mayoría de los modelos de comunicación de la corriente Communication Research, en la primera mitad del siglo pasado en los Estados Unidos, más preocupados por los efectos de los medios desde una perspectiva de masificación y que marcaría la investigación

8 Desde la perspectiva de la comunicación, el modelo de Harold Lasswell, (1948) "quién dice qué a quién, por qué medio y con qué efecto" permite ilustrar los distintos elementos que intervienen en la comunicación, de manera que nos entrega una perspectiva de cada elemento que interviene en este proceso: la elaboración del mensaje al que llamamos noticia y al que lo elabora: el emisorperiodista y las formas que adopta según el medio. 
en esta disciplina casi toda la segunda mitad del siglo XX; visión que sería confrontada por las corrientes de pensamiento de la Economía Política Crítica y los Estudios Culturales.

En el caso particular de los estudios de producción de la noticia o newsmaking, estos dan cuenta de que hay rutinas burocráticas en cada medio como lo establecen Gaye Tuchman en Making Nerws, (1978), Herbert Gans en Deciding what's news (1979) y Michael Shudson en su Sociology of Nerws Production (1989), que muestran como la prensa es una industria que busca formas de estandarización de las prácticas por razones de rentabilidad económica.

Harvey Moloch y Marilyn Lester en: Informar, una conducta deliberada. Del uso estratégico de eventos (1974), elaboran una clasificación para el tipo de eventos construidos por los medios: eventos rutina, escándalos, accidentes y el feliz azar. Así "La estructuración de los contenidos entra en relación con las acciones de los periodistas y con su inserción en conjuntos organizacionales." (En Maigret, 2005: 275)

Con respecto al los criterios de qué es lo que hace de un evento cualquiera que se convierta en noticia, lo explica el concepto de los valores-noticia, que son los criterios de lo que es noticiable, y sirven para establecer una rutina de producción. Golding y Elliot los definen:

Los valores-noticia son utilizados de dos maneras. Son criterios para seleccionar entre el material disponible en la redacción los elementos dignos de ser incluidos en el producto final. En segundo lugar, funcionan como líneas guía para la presentación del material, sugiriendo qué es lo que hay que enfatizar, lo que hay que omitir, dónde dar prioridad en la preparación de las noticias que se presentan al público. Los valores-noticia son por tanto reglas prácticas que incluyen un corpus de conocimientos profesionales que implícitamente, y a menudo explícitamente, explican y dirigen los procesos de trabajo en la redacción. (Golding y Elliot en Wolf: 223)

Los valores-noticia se pueden resumir en: impacto (lo que llama la atención por inusitado y catastrófico), proximidad (importa lo más 
cercano a la realidad del público), relevancia (la importancia de o los personajes que aparecen) y el de la competitividad (lo que reportan otros medios). Paralelamente pueden surgir noticias derivadas de las noticias iniciales al que he identificado como valor noticioso de la derivación o secuela y el valor noticioso de la diversificación que se aprecia en la aparición de nuevas historias que se desarrollan a partir de la noticia original. Este último valor noticioso es desarrollado en el género del reportaje de fondo (Juárez, 2009).

\section{La cuestión metodológica en los estudios de periodismo}

Una tendencia generalizada en algunos investigadores (González Molina, 1986; Hernández Ramírez, 1997; Lozano, 2007; el mismo Shudson, 1989 y otros), al parecer influidos por una tradición que se remonta a los primeros trabajos como los de Galtung y Ruge (1965), desde la perspectiva del análisis de contenido (McQuail, p. 414), conceden una preeminencia al nivel organizativo sobre el individual. Un aspecto que puede aceptarse desde el punto de vista de los trabajadores de la noticia de menor rango, pero que habría que matizar en el caso de los editores y los dueños: "Los editores y los dueños de los medios pueden tomar decisiones en contra de los intereses de su organización o clase social, si mantienen fuertes puntos de vista personales" (Shoemaker y Reese: 254).

A este respecto, en mi propia investigación encontré que esto se daba en el comportamiento de los editores o gerentes en Ciudad Juárez, no sin generar tensiones en la organización (Juárez, 2009).

La tradición de los análisis de contenido, utilizada por los noruegos Galtung y Ruge, ha tenido una fuerte influencia en los estudios de periodismo. Son los investigadores australianos Hanush y Obijiofor (2008), los que señalan algunas consecuencias de la excesiva inclinación de algunos investigadores por esta metodología cuantitativa: E1

9 El análisis de contenido es una técnica de investigación desarrollada por Bernard Berelson (1952), "para la descripción objetiva, sistemática y cuantitativa del contenido manifiesto de la comunicación”. 
estudio de Galtung y Ruge ha recibido considerables críticas. Una critica, por ejemplo, menciona que Galtung y Ruge examinaron el contenido de los periódicos, pero bosquejaron conclusiones acerca del proceso de selección de las noticias (Hjavard, 2002). Otra crítica fue que Galtung y Ruge usan categorías difíciles de definir (Harcup y O'Neil, 2001). No obstante el estudio de Galtung y Ruge se ha convertido en la más influyente explicación de los valores-noticia (McQuail, 1994, p. 270), con un número considerable de investigadores adoptando su marco de trabajo y con la mayor parte de ellos investigando o replicando (sus) argumentos, aunque con algunas modificaciones" (Hanush y Obijiofor, 2008:11-12).

Esto podría explicar un sesgo en el análisis del quehacer periodístico, por la parcialidad epistemológica que deviene al dejar de lado la entrevista, los grupos focales y la observación participante, propios de la investigación cualitativa que exploran el quehacer del actor a partir de su propio discurso explícito. Para ello, se enfocan en el estudio de contenido, análisis del producto mismo del que se infieren conclusiones no matizadas - como es el caso de los editores y los dueños - que derivan, en algunos autores, este privilegiar lo organizacional sobre lo individual.

El rango cuantitativo de información incluye aquellos atributos del contenido mediático que puede ser medido o contado $[\ldots]$ tales medidas pueden proveer información importante sobre cantidades de cobertura y alguna mirada sobre las prioridades, pero no nos pueden decir como fue esa cobertura - los atributos cualitativos del contenido- $[. .$.$] Medir los atributos cualitativos del contenido$ mediático es difícil, pero frecuentemente es mucho más revelador que mirar solo datos cuantitativos. (Shoemaker y Reese: 4)

Esta tendencia generalizada, por el estudio de contenido en la investigación de este campo, no fue ajena en México y Latinoamérica en los 90's. Aunque posteriormente hubo un viraje de esta investigación a partir de metodología cualitativa. 
Para ilustrarlo mejor, Hernández (1997: 220), citando a Michael Shudson, reconoce la debilidad de los estudios conducidos bajo una perspectiva organizacional que centran más su atención en la relación reporteros-funcionarios y dejan al margen la relación reportero-editor; ella concluye que poco se conoce sobre los procesos de escritura, redacción e inclusión de las notas en las emisiones o ediciones de los medios. Esta es quizá una de las 'cajas negras' de la investigación en periodismo, derivada de la escasez de trabajos que partan de herramientas cualitativas como la entrevista y la observación participante del emisor. ${ }^{10}$

Los tópicos de investigación han estado más orientados hacia el receptor, el medio o el mensaje por sí mismo, y no, en cambio, hacia el emisor como sujeto influenciado y condicionado por una realidad contextual, laboral y profesional que podría mediar en su capacidad de producir y generar contenidos y mensajes en el entorno profesional en que se ve inserto. (Mellado, 2010:126)

La postura adoptada en el artículo de Hanush y Obijiofor, es la de que, además del análisis de contenido, perspectiva dominante en las investigaciones de las décadas de los 70 y 80 , se hagan entrevistas a los periodistas para evitar lo que estudios de:

10 Aun cuando el articulo de Hernández es de 1997, en la actualidad no han cambiado mucho las cosas como lo demuestran las ponencias presentadas en dos de los congresos realizados en nuestro país en el 2008, como fueron el de la Asociación Mexicana de Investigadores de la Comunicación (AMIC), en Monterrey N.L. (mayo) y el de la Asociación Latinoamericana de Investigadores de la Comunicación (ALAIC) en el Estado de México (octubre). Además fueron muy escasos los trabajos que contemplaron el uso de más de una metodología, cuantitativa y cualitativa, con un enfoque epistemológico complementario. Las ponencias evidencian, en eventos posteriores, como la AMIC y CONEICC 2010, en la Ciudad de México, que tampoco hubo un cambio significativo. Esto parece que sigue a una tendencia en el resto de Latinoamérica, como lo registra la investigadora chilena Claudia Mellado (2010), que reporta y analiza publicaciones académicas en el periodo 1990-2007. Para el periodo 1990-1999, observa un mayor número de estudios cuantitativos (55.6\%) y muy reducido con enfoque mixto $(16.7 \%)$ para el mismo periodo. Luego registra para el periodo 2000-2007 un viraje hacia lo cualitativo (47.8\%) coincidente con mis observaciones en México, aunque en el uso de enfoques mixtos registra cifras cercanas a las del anterior período (22.8\%). 
Investigadores preocupados por el procedimiento de análisis de contenido pudieron haber desdibujado de la importancia de investigar las razones subyacentes, de por qué los editores de noticias y reporteros seleccionan y reportan las noticias de la manera en la que lo hacen. (p.14). ${ }^{11}$

Más aún, profundizando en una perspectiva holística de los estudios de periodismo, sobretodo cuando se hacen comparaciones en el modo de hacer periodismo en distintos países, estos autores recurren a Mowlana (1997), que:

...recomienda la inclusión de cuatro etapas: la fuente, el proceso de producción, el proceso de distribución, y el proceso de utilización, para hacer esto, los investigadores deben moverse más allá de los modelos políticos, económicos y sociológicos e incorporar marcos de trabajo antropológicos, lingüísticos y socioculturales. (Mowlana citado en Hanush y Obijiofor, 2008)

$\mathrm{Al}$ respecto de los estudios culturales, estos autores precisan que:

El marco de trabajo cultural está compuesto por cuatro dimensiones: por ejemplo las cosmovisiones (incluidos aspectos como la religión) sistema de valores (nacionalismo, individualismo-colectivismo, masculinidad-feminidad, instancias de poder, rechazo a la incertidumbre, y la orientación a largo y corto plazo) sistemas de organización social (incluyendo factores políticos, económicos históricos y geográficos) y sistemas de representación simbólica (interesados en asuntos como el lenguaje y sistema mediático). Todas las dimensiones están interrelacionados y en un momento dado habrá diferentes grados influencia de cada una de ellas. (Hanush y Obijiofor, 2008: 18)

11 Estas consideraciones fueron atendidas en mi propia investigación de tesis de maestría (Juárez, 2009) 
Hasta ahora se conocen muy pocos trabajos con esta perspectiva, tal vez porque requieren de mayor tiempo y recursos en su realización. Situación difícil de cubrir por un solo investigador.

\section{La profesión del periodismo}

Merece un apartado especial la obra de Gaye Tuchman que analiza, en Making Nerws: A Study in the Construction of Reality (1978), el papel mediador de la noticia entre las instituciones y el público; por un lado, refleja distintas relaciones en lo público/privado y por otro, posee distintas valoraciones del término "hecho". Así, objetiva los sucesos susceptibles de convertirse en noticia y los inserta en una clasificación de lo que es 'noticiable'.

Tuchman, sostiene que en el rol legitimado del periodista, el atributo esencial y más importante es la objetividad, que le confiere, a su vez, un estatus social que será mayor cuanto más alto sea el nivel de sus fuentes de información. Esto es importante ahora que esta presente la discusión de que tan legítimo profesionalmente hablando es el periodismo practicado por ciudadanos comunes en las redes sociales de la Internet, en lo que se ha dado en llamar citizen journalism o periodismo ciudadano.

Volviendo al concepto de construcción de la noticia por el periodista, hay implícito un problema: las consecuencias de esa realidad construida o re-presentada.

Walter Lippman, reconoce que hay una realidad percibida por el ciudadano y que este actúa a partir de esa realidad percibida.

En su teoría del pseudoentorno, expuesta en su trabajo Public Opinion (1925), Lippman nos habla de las implicaciones de lo que él denomina las 'ficciones', que componen este pseudoentorno y sus consecuencias en la sociedad:

Ciertamente, en el nivel de la vida social, lo que se ha dado en llamar la adaptación del hombre a su entorno, tiene lugar a través de ficciones (...) por ficciones no me refiero a mentiras. Sino a una representación del entorno que en 
mayor o menor grado es elaborado por el hombre mismo. (Lippman: 3)

El pseudoentorno, entonces, es generado por las percepciones que tienen como origen, entre otras cuestiones, la información difundida a través de las noticias. El problema deviene cuando a partir de estas ficciones se actúa - hay consecuencias en el entorno-, en la realidad misma. Una idea que recupera Maxwell McCombs (2006), en su teoría de la agenda setting cuando nos propone que los medios le plantean al público una agenda en qué pensar. En otras palabras, imponen a la opinión pública los temas que estarán presentes. Recordemos aquí, por ejemplo, la fuerza con la que fue impuesta, por los medios mexicanos en mayo del 2009, la agenda monotemática (los demás temas prácticamente fueron borrados de los noticieros) del brote de una cepa, percibida como peligrosa, de un virus de la influenza. ${ }^{12}$

A propósito de esa realidad 'construida', a partir de la noción de Robert Park en cuanto que la noticia es una forma de conocimiento, el investigador brasileño Eduardo Medistsch señala con cierta mordacidad que:

(...) el periodismo es una forma de producción de conocimiento. Sin embargo, en nuestra práctica cotidiana, uno puede verificar que esta forma de saber, mientras que puede ser usado para reproducir otras piezas de conocimiento, puede ser usado también para degradarlo, y es probable que en muchas instancias, simultáneamente, se las arregle para lograr ambas. (Medistsh, 2005: 2) ${ }^{13}$

12 La empresa IBOPE (2010), dedicada a la medición de audiencias, reportó el registro más alto de sintonía, hasta ese momento, en la historia de la televisión mexicana. Efecto postulado por la teoría de la dependencia mediática de Ball-Rokeach y DeFleur, en su trabajo "A Dependency Model of Mass Media Effects" (1976).

13 Traducción propia: "journalism is a form of knowledge production. However, in our everyday practice, one verifies that this form of knowledge, while it can be used to reproduce other items of knowledge, can also be used to degrade it, and it is probable that in many instances it manages to accomplish both, simultaneously." 
Quizá habría aquí que colocar en esta perspectiva, al periodismo sensacionalista o amarillista que exagera — cuando no deforma- los hechos que se narran.

Esta es la preocupación central del análisis desde la perspectiva del emisor. Pero ¿qué hay del problema de la objetividad periodística, aun cuando es enunciada como parte de esta profesión como ya lo hemos visto en Tuchman? Para los académicos no es un problema en estricto sentido: "La objetividad o búsqueda de la verdad en los periodistas, es una <objetividad práctica> mediada por las restricciones y el control organizacional e institucional" (Cervantes, 2005: 114). Así que la cuestión, no radica en el informar objetivamente, sino en el qué y cómo se informa, es decir, que selección y tratamiento se hace de lo que es 'informable'.

\section{Los filtros en la información}

El concepto del gatekeeper es el que mejor describe el proceso de filtro que se da en la construcción del hecho como noticia.

El término gatekeeper ${ }^{14}$ corresponde a la noción creada por el psicólogo social Kurt Lewin (1947), aplicada luego por David Maning White $(1951)^{15}$, autor que centra su estudio en los individuos considerados aisladamente que actúan en las empresas periodísticas, seleccionando las informaciones que llegan a ellas acerca de los acontecimientos ocurridos, al considerarlas como más relevantes o de mayor interés para una determinada audiencia.

Lorenzo Gomis precisa: "la función del gatekeeper es importante, porque de él depende el flujo de la información y él decidirá silenciosa e inapelablemente si una noticia se da o no se da." (Gomis, 1991: 82).

14 Algunos autores mexicanos como Cervantes Barba, o Lozano Rendón, lo traducen como 'guardabarreras'. Mientras que otros, Bagdikian (1975) por ejemplo, en la traducción al español, aplican el término 'selector'. Ambos términos son usados por Rodrigo Alsina (1989), aquí se usan indistintamente.

15 En entrevista telefónica de Stephen Reese con David M. White, este último acepta que el término lo toma de su maestro Kurt Lewin cuando coinciden en la Universidad de Iowa (Reese, 2001) 
Sin embargo, 'la metáfora del gatekeeper', como la llama críticamente Michael Shudson (Shudson en Lozano 2007), no explica ampliamente el porqué de los criterios de selección, por lo que al parecer estos se ejercerían por un solo individuo y no serían producto de las rutinas de la organización (Shudson en Hernández, 1997 y en Lozano, 2007).

No obstante esta posición, en mi propia investigación (Juárez, 2009) y acorde con Shoemaker y Resse (1991), pude corroborar, que en cierto nivel de la misma organización, el editor y en última instancia el dueño cumplen cabalmente con lo que se espera del gatekeeper. el 'filtraje' y paralelo a esta función, la manera de contar la historia. Por lo que he propuesto dos nuevos términos que distinguen los niveles de decisión de este proceso: selector ejecutivo (top gatekeeper) que es el editor o gerente - en última instancia el dueño del medio- y selector subordinado (subordinate gatekeeper), quienes intervienen en la recopilación de la noticia: reporteros, fotógrafos, camarógrafos (Juárez, 2009).

La labor del filtraje, a veces no será de manera tan silenciosa o discreta como lo suponen Gomis (1991) o el mismo Warren Breed, que en su investigación pionera, Social Control in the News Room (1955), señaló que las políticas de la empresa se le hacían saber al reportero a través de una especie de censura implícita, que el editor ejercía sobre sus reporteros, de lo que se sigue que las normas son seguidas por todos los empleados del periódico si quieren ascender, o en el último de los casos conservar el trabajo.

Breed encontró, que de esta manera, la conducta del gatekeeper (editor) da los indicadores necesarios para el manejo informativo, a veces, sin que se expongan las razones reales de tal comportamiento. Esto debido a una cultura democrática basada en la libertad de expresión, contenida en la primera enmienda de la Constitución de los Estados Unidos.

Aun con el derecho a la libertad de expresión contenido en la constitución norteamericana, desde un enfoque crítico que los ubica en la corriente de la Economía Política de la Comunicación, Noam Chomsky y Edward Herman en Manufacturing Consent (1988), establecen 
cinco filtros que intervienen en el proceso del gatekeeping (selección de las noticias) que ellos puntualizan a partir de medios en manos privadas y que se convierten en los "perros guardianes" de los intereses de la élite económica en el poder. Estos cinco filtros son: la concentración de la propiedad de los medios pertenecientes a conglomerados corporativos; el financiamiento de la publicidad que alinea las políticas informativas con los intereses de los patrocinadores; la dependencia de información suministrada por el gobierno, las empresas o los 'expertos' (fuentes de información); el uso de correctivos para disciplinar a los periodistas como la crítica (flak) por entidades con cierta credibilidad, afines a los intereses del establishment, y por último, el etiquetamiento de "comunista" y "antipatriota" a todo aquel que no haga coincidir su visión con las políticas hegemónicas de la élite, particularmente en asuntos internacionales. ${ }^{16}$

\section{La complejidad del ejercicio periodístico}

Pero entonces ¿`cómo resolver la cuestión de la objetividad, entendida como el no involucramiento en los hechos que se narran y el compromiso con la comunidad? Tenemos entonces, al periodista 'imparcial', cuya labor presumiblemente es ofrecer la información tal y como se presenta, paralelamente, está el periodista defensor de alguna causa justa. Para zanjar la cuestión, en los años sesenta se introduce el modelo del advocate o defensor, concepto que pretende explicar al periodista que toma una posición a favor de algún grupo en desventaja frente al poder: "El periodista advocate considera que su rol de periodista va

16 Hay una línea de investigación que cuestiona que pueda seguirse a la figura del gatekeeper tal como se entendía en sus orígenes. En trabajos como "Unchained reaction. The collapse of media gatekeeping and the Clinton-Lewinsky scandal" de Williams y Delli Carpini (2000), se plantea la emergencia de la Internet como otro medio de donde se puede obtener información, además de los programas de entretenimiento como los llamados "tabloids", que espectacularizan los escándalos; estos son considerados "pequeñas puertas" por donde se filtra la información, lo que hace pensar que ya no hay selectores en un papel relevante. 
unido a su rol de ciudadano, el periodista vive y participa en una colectividad, sería el periodista comprometido"(Alsina: 153).

Tal vez por eso Maigret (2005) reflexiona sobre los retos del estudio de los productores de sentido, al situarlos en situaciones de multinivel en el contexto de una competencia por los públicos a que se ven arrojados por la propia dinámica social (me suscribo esta posición), que relativiza el determinismo crítico, que acusa el mismo trabajo de Pierre Bourdieu y que Eric Maigret mismo acusa como un exceso determinista (Maigret: 285), pues Bourdieu llega al extremo de calificarlos como marionnettes de la necesite (marionetas de la necesidad), y excluye en su concepción las dinámicas relacionales plurales de una sociedad democrática. ${ }^{17}$

Es conveniente recordar que la noticia, está influida por muchos factores como lo aclara Eliseo Verón en su obra La construcción del acontecimiento:

Los factores en juego en el funcionamiento de las comunicaciones masivas van más allá de la voluntad de los individuos que participan en su producción. Nuestras palabras, en su condición de sujetos sociales, están determinadas por leyes que aplicamos en forma espontánea aun cuando pretendemos negar su existencia. (Verón, 2002: III)

Precisamente es Teun Van Dijk, el que nos ayuda a entender el porqué, en un mismo hecho, se destacan algunos aspectos y otros se soslayan al ser narrados de distintas maneras, tantas como periodistas se ocupen del suceso:

Las proposiciones que aparecen primero en la jerarquía de una representación de un texto y/o que tengan muchos vínculos con otra información <y estos pueden ser los llamados detalles sobresalientes que son frecuentemente conmovedores, escandalosos o graciosos >, serán las mejor recordadas o las que se seleccionan primero cuando pre-

17 El trabajo de Bourdieu donde aparece la cita es: Sur la telévision. L'Emprise du journalisme (1996). "Sobre la televisión. La empresa del periodismo". 
guntemos cuál fue el asunto, el tema o la información más importante de un texto. Las variaciones sobre los temas se deben a las diferencias de estado cognoscitivo: naturalmente, si los sujetos tienen diferentes objetivos, intereses y conocimientos, producirán resúmenes y recapitulaciones mnemónicas parcialmente diferentes. (Van Dijk, 2007: 92)

Maigret mismo dice en un orden de ideas aceptable: (sería mejor considerar, que) "Más allá del nivel organizacional y cognitivo, la pluralidad de roles puede leerse a partir de una sociología comprehensiva, los periodistas de información enfrentan unas dificultades de tipo formal en el marco de un contexto histórico preciso" (Maigret, 2005: 289).

Ahí están las nociones de servir a la construcción del espacio público, y en lo político, la de ejercer un contrapoder, como lo sustenta Denis McQuail (2000).

En México y particularmente en Ciudad Juárez, este asunto del equilibrio al poder del estado, se ha vuelto un tema particularmente sensible para los periodistas, cuando tienen que ejercer una profesión en medio de presiones - como las mismas amenazas a la vida— que reciben desde los distintos bandos involucrados en la guerra por los territorios de trasiego y distribución de sustancias ilegales, y de algunos individuos o sectores gubernamentales proclives al ejercicio de la censura a través de prácticas soterradas o explícitas.

\section{Referencias bibliográficas}

Alsina, Miguel. La construcción de la noticia. Barcelona: Paidós, 1989. Arriaga,José Luis. “La nota roja: 'Colombianización' o 'mexicanización' periodística”, en: Sala de Prensa, no. 45, año 4, vol. 2, 2002.

Arroyabe, Jesús. Reflexiones sobre el cubrimiento al conflicto armado en Colombia. Ponencia, IX Congreso de la ALAIC. ITESM, Tlanepantla, Edo. de México, 2008.

Bagdikian, Ben. Las máquinas de información. Fondo de Cultura, México D.F., 1977. 
Barzilai-Nahon, K. "Gatekeeping: A Critical Review", en: ARISTAnnual Review Of Information Science And Technology-, February, University Of Washington, 2008.

Berger, Peter y Luckmann, T. La construcción social de la realidad, Ed. Amorrortu, Buenos Aires, Argentina, 1999.

Castillo, Leticia. Noticias y culturas en Ciudad Juárez, Tesis de Maestría en Ciencias Sociales, Universidad Autónoma de Ciudad Juárez, 2001.

Cervantes, Cecilia. "Valores noticiosos en el periodismo de nota roja. Búsqueda articulada de indicadores empíricos", en: Comunicación y Sociedad, núm. 25-26, DECS, Universidad de Guadalajara, 1995, pp. 89-137.

-. "Construcción primaria del acontecer y planeación de la cobertura informativa. Propuesta metodológica para su estudio", en: Comunicación y Sociedad, U. de G., núm. 28, septiembre-diciembre, 1996, pp. 49-81.

- "El estudio de los productores de noticias: desarrollo internacional y avances de investigación en México", en La comunicación en México: diagnósticos, balances y retos, Lozano J.C. editor, CONEICITESM, 2005, pp. 91-124.

Dimmick, J. y P. Coit."Levels of analysis in mass media decision making.A taxonomy, research strategy and ilustrative data analysis", Mass Communication Review Yearbook, vol. 4. Beverly Hills: Sage, 1983.

Hanush, Folker y Obijiofor, Levi. "Toward a More Holistic Analysis of International News Flows", en: Journal of Global Mass Communication, volume I, no. 1 / 2., 2008 pp. 9-21.

González, Gabriel. The production of Mexican television news. The supremacy of corporate rationale. Tesis de Doctorado $(\mathrm{PhD}$ in Mass Communications) University of Leicester, Centre for Mass Communication Research. Gran Bretaña, 1989.

Gomis, Lorenzo. Teoría del periodismo, cómo se forma el presente. Barcelona: Paidós Comunicación, 1991.

Habermas, Jurgen. Teoría de la acción comunicativa, Tomo I, Ed.Taurus, México D.F., 2005. 
Herman, Edward y Chomsky, Noam. Manufacturing Consent: The Political Economy of the Mass Media, Phanteon Books, Chicago, 1988.

Hernández, María Elena. ¿Qué son las noticias?, en: Comunicación y sociedad, núm. 14-15, enero-agosto, 1992, pp. 235-250.

- "La sociología de la producción de noticias. Hacia un nuevo campo de investigación en México", en: Comunicación y sociedad, núm. 30, mayo-agosto, 1997, pp. 209-242.

Igartúa, José y Humanes, María Luisa. Teoría e investigación en comunicación social, Ed. Síntesis, Madrid, España, 2004.

Juárez, Ernesto Pablo. Los criterios de selección y jerarquización de las noticias en los medios de Ciudad Juárez, Chibuabua: los eventos del CERESO en el 2007, tesis de maestría, Universidad Autónoma de Chihuahua, Ciudad Juárez, México, 2009.

Lasswell, Harold. "The Srtucture and Function of Communication in Society" en Lyman Bryson (ed.) The Communication of Ideas, Institute for Religious and Social Studies, Harper and Row, Nueva York, 1948.

Lippman,Walter. Public Opinion, disponible en Internet: <http:// xroads.virginia.edu/ Hyper/Lippman/cover.html> (febrero, 2008), 1925.

Lozano, José Carlos. Teoría e investigación de la comunicación de masas, Pearson Educación, México, 2007.

Marques de Melo, José. Conferencia magistral en el LX Congreso de la Asociación Latinoamericana de Investigadores de la Comunicación, I.T.E.S.M.Tlanepantla, Edo. de México, 2008.

Maigret, Eric (2005). Sociología de la comunicación y de los medios, F.C.E., México.

Meditsch,Eduardo."Journalism as a Form of Knowledge: a Qualitative Approach”, Brazilian Journalism Research, volume 1, number 2, semester 2, Brasilia, Bra., 2005.

Mellado, Claudia. "Análisis estructural de la investigación empírica sobre el periodista latinoamericano", Comunicación y Sociedad. núm.13, enero-junio, 2010, pp.125-171. 
McCombs, Maxwell. Estableciendo la agenda, Ed. Paidós Ibérica, Madrid, 2006.

McQuail, Denis. Introducción a la teoría de comunicación de masas, Ed. Paidós, Barcelona, 2000.

Orozco, Guillermo. La investigación en comunicación desde la perspectiva cualitativa, Universidad Nacional de la Plata-IMDEC A.C., Guadalajara, México, 1997.

Park, Robert. "News as a Form of Knowledge: A Chapter in the Sociology of Knowledge", American Journal of Sociology, 45: 1940, pp. 669-686.

Pedroso, Rosa. "Elementos para una teoría del periodismo sensacionalista", en: Comunicación y Sociedad, U. de Guadalajara, 1994, pp. 139-157.

Reese, Stephen. "The Roots of Sociology of News: Remembering Mr. Gates and Social Control in the Newsroom", en:J E MC Quarterly, vol. 78, núm. 4, 2001, pp. 641-648.

Shoemaker, Pamela y Reese, Stephen. Mediating the Message, Theories of Influences on Mass Media Content, second edition, Longman, 1996.

Tuchman, Gaye. Making Nerws: A Study in the Construction of Reality, Free Press, 1978.

White, D. M. "The Gatekeeper: A Case Study in the Selection of News", en Journalism Quarterly, núm. 27, 1950.

Weber, Max. "Para una sociología de la prensa", en: Revista Española de Investigaciones Sociológicas, núm. 57, 1992.

Williams, B. A. \& Delli Carpini, M. "Unchained reaction. The collapse of media gatekeeping and the Clinton-Lewinsky scandal". Journalism. Theory, practice E criticism, 1(1), 2000, pp. 61-85.

Wolf, Mauro. La investigación de la comunicación de masas, Ed. Paidós Mexicana, México, D.F., 2002.

Van Dijk, Teun. Estructuras y funciones del discurso, Siglo XXI editores. México, 2007.

Verón, Eliseo. Construir el acontecimiento, Gedisa, Barcelona, España, 2002. 